Perceived Satisfaction with Public Transport Service in Nine European Cities

Author(s): Markus Fellesson and Margareta Friman

Source: Journal of the Transportation Research Forum, Vol. 47, No. 3 (Public Transit Special Issue 2008), pp. 93-103

Published by: Transportation Research Forum

Stable URL: http://www.trforum.org/journal

The Transportation Research Forum, founded in 1958, is an independent, nonprofit organization of transportation professionals who conduct, use, and benefit from research. Its purpose is to provide an impartial meeting ground for carriers, shippers, government officials, consultants, university researchers, suppliers, and others seeking exchange of information and ideas related to both passenger and freight transportation. More information on the Transportation Research Forum can be found on the Web at www.trforum.org. 


\title{
Perceived Satisfaction with Public Transport Service in Nine European Cities
}

\author{
by Markus Fellesson and Margareta Friman
}

The present study provides a transnational comparison of the perceived service satisfaction with public transport in eight European countries. Data was collected from 9,542 respondents in Stockholm, Barcelona, Copenhagen, Geneva, Helsinki, Vienna, Berlin, Manchester, and Oslo. The respondents rated their agreement with 17 attribute-related statements regarding local public transport services. Using factor analysis, this study identifies the four satisfaction dimensions of system, comfort, staff, and safety, which were present in most, but not all of the cities. These findings indicate that there are differences in how public transport is perceived. This needs to be addressed in order to make comparison meaningful. Different explanations for these diverse findings are discussed.

\section{INTRODUCTION}

What drives satisfaction with public transport? Although there are some exceptions (Friman, Edvardsson \& Gärling 1998, Morfoulaki, Tyrinopoulos \& Aifadopoulou 2007), this question has not been extensively dealt with in transport research. Instead, research is dominated by choice modeling and stated preference approaches (cf Henscher \& Prioni 2002), if cognitive perspectives are taken into account at all.

However, satisfaction is an important concept that deserves further interest. From consumer research, satisfaction is known to be of great value in understanding customers' perceptions and evaluations (Oliver 1997), repeatedly showing itself to be an important indicator of future customer behavior (Fornell 1992, Johnson \& Gustafsson 2000). Customer satisfaction, therefore, highlights and explains the link between what a company does (in terms of the products and services offered) and how its customers react. For public transport, this link is a key concern.

In many countries, major investments are being made in public transport systems in order to make them more competitive with other means of transport, most notably private cars. New services are being developed and old ones are being improved. However, an increase in supply (qualitatively or quantitatively) will not automatically lead to a corresponding increase in demand and satisfaction (cf. Fujii \& Kitamura 2003, Mackett \& Edwards 1998). To make sure that investment really attracts the existing and potential customers expected, knowledge of satisfaction should provide policymakers and operational managers in the public transport system with valuable information. In particular, satisfaction studies can provide decision makers with information about what customers consider important, as well as information about how the existing public transport service is perceived as performing in these dimensions. For example, previous studies in public transport (Friman, Edvardsson \& Gärling 2001, Friman \& Gärling 2001) have shown that employee behavior is an important consideration for the traveler. Low satisfaction scores in this area indicate that investments should be directed towards staff training and incentives related to employee behavior. Drawing such managerial implications, however, requires a firm knowledge not only about satisfaction levels for individual attributes, but also about overall dimensional structure of these attributes.

The dimensional structure of satisfaction measures is also important in performance-based contracts (Henscher \& Stanley 2003), which have become increasingly popular in the public transport sector in line with the general trend toward market orientation in that sector (cf. Osborne \& Gaebler 1992). Customers' subjective experiences are then used in tandem with objective measures to monitor and evaluate suppliers' performance. This requires a comprehensive, yet manageable set of measures that covers all relevant areas of the customer experience. Understanding the cognitive 
structure of this experience is pivotal for developing and implementing such a comprehensive measurement system.

To summarize, satisfaction is increasingly being put forward as key to the future development of public transport, both in theory and in practice. In transport research, satisfaction is sometimes touched upon from a policy perspective (cf. Hensher 2007). There is also a small but growing number of empirical studies that illustrate the concept using data from public transport users (cf. Friman, Edvardsson \& Gärling 2001, Friman \& Gärling 2001), as well as from private car users (e.g. Beirão \& Cabral 2007). There are also studies where satisfaction is used as an "effect" variable, e.g. when improvements in the public transport system are to be evaluated (cf. Friman 2004, Mackett \& Edwards 1998, Wall \& McDonald 2007). Attributes like reliability, frequency, comfort, information, driver behavior, and cleanliness are shown to be key elements of public transport user satisfaction (Bates et al. 2001, Beirão \& Cabral 2007, Friman \& Gärling 2001, Hensher et al. 2003). These and similar studies have made important contributions to our understanding of what public transport satisfaction is, and what is actually satisfying. However, the concept itself is seldom systematically analyzed. This is somewhat surprising considering the conceptual foundations of customer satisfaction have been a topic of extensive debate in consumer research and its associated fields for several years. In this paper, we argue that the increased use of customer satisfaction in public transport warrants a similar discussion of the concept, taking into account insights from general satisfaction research, as well as the specific conditions of the sector.

The objective of this study is to identify factors that travelers in nine different European cities use to evaluate public transport. Furthermore, we compare and contrast these findings, both between the surveyed cities and with previous research.

\section{SATISFACTION AND SERVICE QUALITY DIMENSIONS}

Previous customer satisfaction research has shown that satisfaction is a multidimensional construct (Oliver 1997). Furthermore, particularly in service research, the idea of a generic structure of quality factors composing the overall satisfaction response has received a great amount of attention. An early example of this is Grönroos' $(1984,2000)$ model of service quality as consisting of two broad groups of service attributes - technical and functional - corresponding to what the customer receives and how he/she receives it. In line with this tradition, several attempts have been made to specify this broad dichotomy further, with the aim of finding more specific, yet still generic dimensions of service quality. In an ambitious research program, Parasuraman, Zeithaml, and Berry (1985, 1994) and Zeithaml, Berry, and Parasuraman (1988) identified five such generic service dimensions: reliability, assurance, tangibles, empathy, and responsiveness. These or similar dimensions have been widely used in service research and practice (including in Parasuraman et al.'s own SERVQUAL instrument). In a later review by Edvardsson (1996), more than 30 studies of customer PSQ (perceived service quality) were examined. They showed that how the employees treat the customers, the reliability of the service, simplicity (e.g. the clarity and availability of information), and recovery when something goes wrong are all significant factors. The findings are well in line with the model of Parasuraman et al. (1985), with the notable exception of tangibles, which are not identified as a separate factor in the Edvardsson review.

Such generic dimensions have an inherent appeal, as they provide a stable framework for students of customer satisfaction across a multitude of empirical settings. However, concerns have been raised about their general applicability, as well as over their conceptual underpinnings (Buttle 1996, Cronin \& Taylor 1992, Teas 1993). Some of the objections are that the dimensions identified are not valid (or meaningful) in all service industries, that they are not exhaustive, and that they do not take into account differences between various customer groups and cultures.

It could also be argued that the dimensions of Parasuraman et al. (1994) are adapted to service situations dominated by personal interaction between customers and service employees. This could make them difficult to apply to services like public transport, which are more reliant on technical 
systems and physical artifacts. In the aforementioned study by Friman (2001), for example, it was shown that tangibles and system properties were prominent features of the service experience.

Without going into details regarding the critique against the generic models and the ensuing debate, it makes sense to apply the idea of generic service quality dimensions with some care. Even within the same industry, there might be considerable differences in how the service is perceived by the customers, due to various ways of producing the actual service and due to customer differences. Such differences do not reduce the value of satisfaction measurement, however. They could indicate fundamental aspects of the service industry under study that should especially be attended to.

Furthermore, a dimensional structure that does emerge, despite differences being taken into account, could reasonably be argued to capture the true generic nature of customer perceptions of the industry. That is, by avoiding conceptual lock-ins to presumed global dimensions, natural and contextually derived, but industry level, generic dimensions might be identified. Deriving such underlying dimensions of the European public transport industry from a multitude of service attributes is the aim of the present study, wherein we analyze the factorial structure of a number of aspects commonly used in public transport market research (cf. the European Committee for Standardization 2002).

\section{METHOD}

The sample used in this study was obtained from Benchmarking in European Service of Public Transport (BEST 2006), where citizen satisfaction with public transport has been measured by means of an annual survey conducted in several European cities from 2001. Our selected sample is the survey conducted in nine cities in 2006, consisting of people between the ages of 16 and 96 .

\section{Procedure}

The data was collected via telephone survey. The respondents were selected at random and telephoned between $5 \mathrm{p} \mathrm{m}$. and 9 p.m. They were informed about the purpose of the survey, which was to obtain information about various aspects of citizen satisfaction with public transportation, and were then asked to participate in a telephone interview. Those who declined to participate in the survey were asked why they had chosen not to participate; the most common reason given was that they did not use public transportation and thus did not want to participate. The respondents who did not answer were called again up to six more times in order to obtain as high a level of participation as possible. Data collection was terminated when the interviewers had reached and collected data from 1,000 respondents in each city

Data was collected by local survey institutes in each city. These local institutes were responsible for translating the questionnaire into the local language. The questionnaire has also been back translated (i.e. verified by a translation agency).

\section{Questionnaire}

The questions asked concerned the respondents' opinions about public transport services. The respondents stated whether they agreed or disagreed with different statements about public transport attributes. Seventeen attributes were rated. All ratings used the following scale: (1) don't agree at all, (2) hardly agree,(3) neutral, (4) partially agree, and (5) fully agree. They also answered some background questions. 


\section{RESULTS}

\section{Sample description}

The total sample of 9,542 obtained from all nine cities had a gender breakdown of $39 \%$ male and $59 \%$ female. The mean age was 49.4 years ( $\mathrm{SD}=17.6$ years). Forty-five percent of the respondents were working full time, 10\% were working part time, $8 \%$ were students, $26 \%$ were retired, and $7 \%$ were occupied with other things. Two thousand nine hundred and twenty-four respondents (32\%) reported that they were daily users, 2,447 (26\%) respondents were weekly users, 1,817 (20\%) respondents were monthly users, and 1,818 respondents $(20 \%)$ used public transport seldom or never.

\section{Factor Analysis}

The 17 items of the survey were subjected to factor analysis, using SPSS 15, during which principal component analysis (PCA) was used to obtain the initial solutions (varimax rotation) (Henson \& Roberts 2006). Separate analyses were conducted for each city with the aim of summarizing the information contained in the original attributes (variables) into smaller sets of composite dimensions. In this study, the eigenvalue $\geq 1.0$ rule (Kaiser 1960) was used to determine the numbers of factors to retain. Items with high loadings on several factors were deleted, as were items with very low communalities (<.40, Hair et al. 1998). To assess the internal reliability of the factor identified, a Cronbach's coefficient alpha was calculated.

Table 1 presents the full factor matrix for each city.

In Stockholm, the PCA yielded three factors with eigenvalues $\geq 1.0$, which jointly accounted for $56.3 \%$ of the overall variance. The eigenvalues of those factors were 5.5, 1.5, and 1.2. All factors have a reliability (Cronbach's alpha) greater than 0.68 .

In Barcelona, principal component analysis yielded three factors with eigenvalues $\geq 1.0$, which jointly accounted for $61.2 \%$ of the overall variance. The eigenvalues of those factors were 5.8, 1.5 , and 1.2. All factors have a reliability greater than 0.72 .

In Copenhagen, principal component analysis yielded four factors with eigenvalues $\geq 1.0$, which jointly accounted for $60.0 \%$ of the overall variance. The eigenvalues of those factors were $5.8,1.5$, and 1.2. All factors have a reliability greater than 0.67 .

In Geneva, principal component analysis yielded four factors with eigenvalues $\geq 1.0$, which jointly accounted for $56.2 \%$ of the overall variance. The eigenvalues of those factors were $5.8,1.5$, and 1.2. All factors have a reliability greater than 0.65 .

In Vienna, principal component analysis yielded four factors with eigenvalues $\geq 1.0$, which jointly accounted for $60.1 \%$ of the overall variance. The eigenvalues of those factors were 5.8, 1.4 , 1.3 , and 1.1. All factors have a reliability greater than 0.58 .

In Berlin, principal component analysis yielded four factors with eigenvalues $\geq 1.0$, which jointly accounted for $59.4 \%$ of the overall variance. The eigenvalues of those factors were $5.5,1.3$, 1.2, and 1.1. All factors have a reliability greater than 0.66 .

In Manchester, principal component analysis yielded four factors with eigenvalues $\geq 1.0$, which jointly accounted for $64.2 \%$ of the overall variance. The eigenvalues of those factors were $5.5,1.3$, 1.2 , and 1.1. All factors have a reliability greater than 0.71 .

In Oslo, principal component analysis yielded four factors with eigenvalues $\geq 1.0$, which jointly accounted for $61.0 \%$ of the overall variance. The eigenvalues of those factors were $5.5,1.3,1.2$, and 1.1. All factors have a reliability greater than 0.71 .

In Helsinki, principal component analysis yielded four factors with eigenvalues $\geq 1.0$, which jointly accounted for $54.3 \%$ of the overall variance. The eigenvalues of those factors were 5.1, 1.4, 1.1, and 1.0. All factors have a reliability greater than 0.61 . 


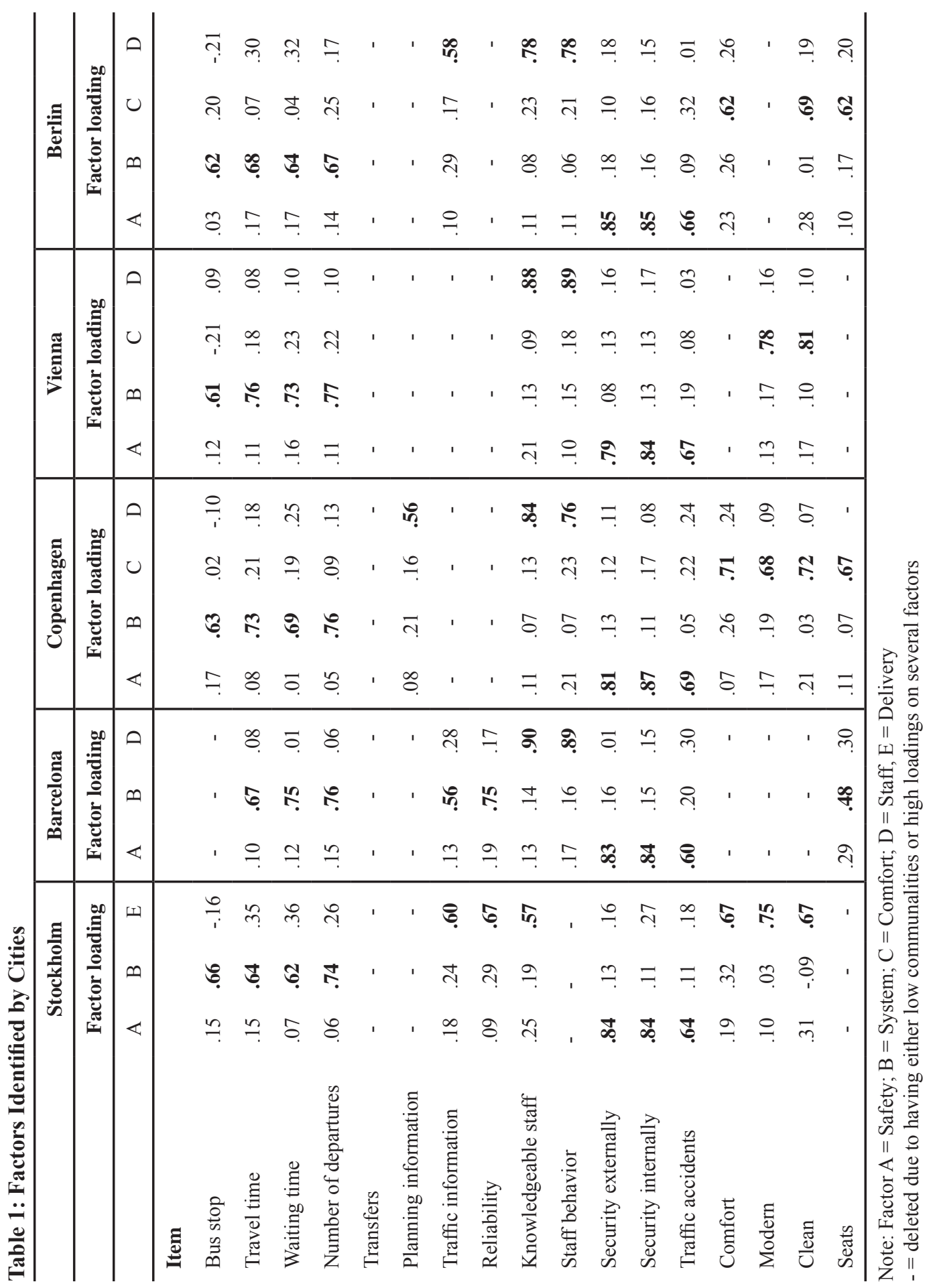




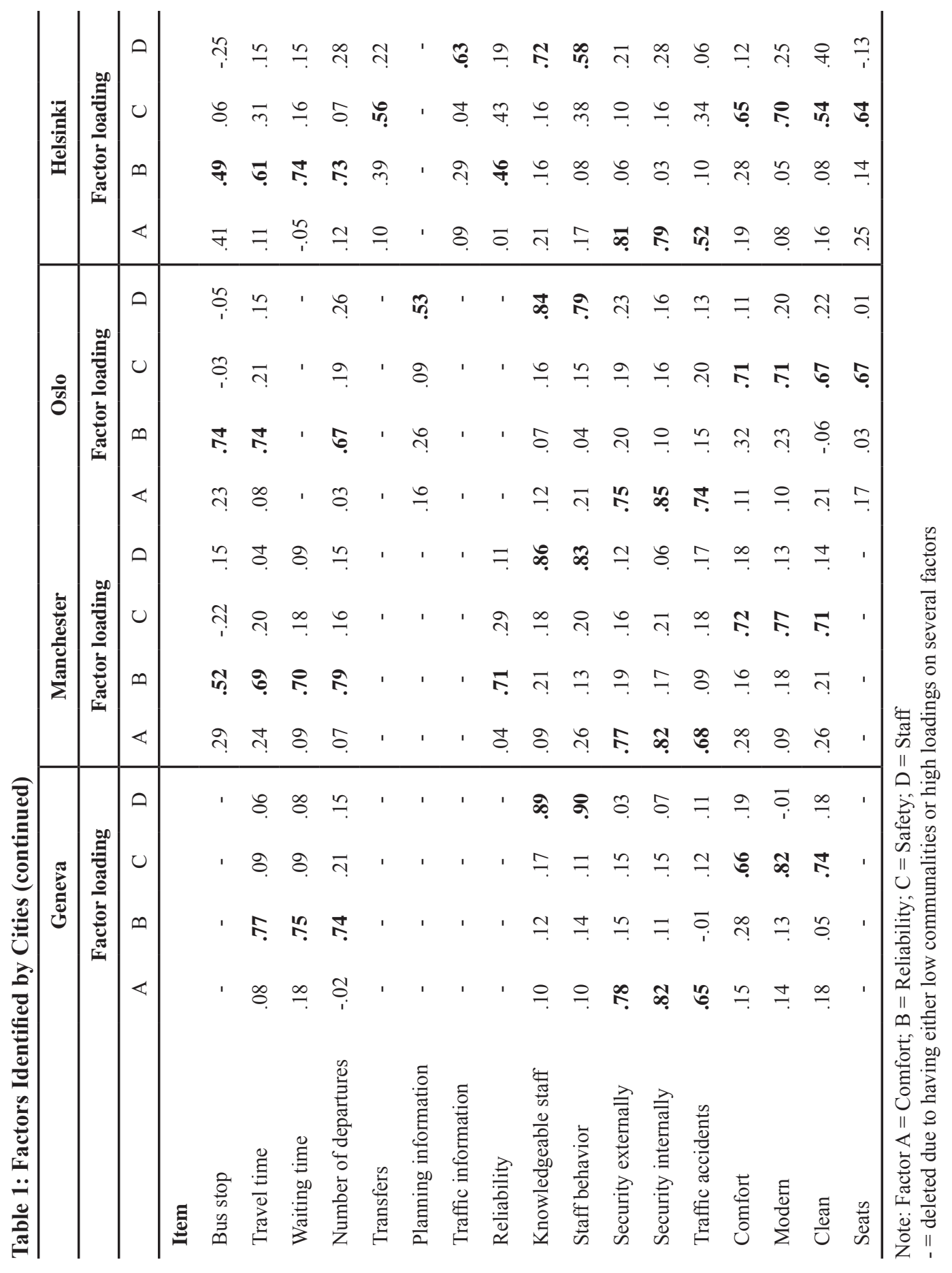


The analysis identified two dimensions appearing in all nine cities. These factors are called Factors A and B. The items measuring these dimensions are not identical across the nine cities, but are very similar. Factor A we interpreted as safety, because it consists of three items related to feeling secure at stations and on board buses and trains. Items in Factor B primarily relate to reasonable travel and waiting times, as well as satisfaction with the number of departures. In some cities, a reliability item (PT runs mostly on schedule) and an item measuring accessibility to stops also loaded highly on this factor. We thus identified this factor as a system factor.

Factor $\mathrm{C}$ appears in seven of the nine cities. It primarily reflects how comfortable it is to travel by PT, how modern and clean the buses and trains are, as well as satisfaction with the number of seats. Factor $\mathrm{C}$ was identified as a comfort factor. This factor was not identified in either Stockholm or Barcelona. In Stockholm, measures relating to comfort were instead related to items measuring staff behavior. Thus, this combined factor, Factor E, was identified as relating to delivery. In Barcelona, these items loaded highly on all factors and were therefore dropped from the analysis.

Similarly, Factor D appears in eight of the nine cities. Measures of staff behavior (whether staff are knowledgeable and behave correctly) loaded highly on Factor D and was thus identified as a staff factor. In some cities, a reliability item (PT runs mostly on schedule) also loaded highly on this factor. This may be due to departures or arrivals according to plan being dependent on the driver's driving behavior. As mentioned above, the exception is Stockholm, where Factor C (comfort) is combined with Factor D (staff), thus constituting a new factor describing service delivery (Factor E).

\section{DISCUSSION}

The overall pattern of factors shows clear signs of an industry generic structure consisting of four basic quality dimensions, i.e. safety/security, system (with supply and reliability items), comfort, and staff behavior. This clearly indicates that that there is, in fact, a uniform way of perceiving public transport in major European cities. On a general level, the findings are also in line with previous research into service quality. The system factor clearly relates to what the customer gets (i.e. the technical service quality (Grönroos 1984, 2000)), while the other three dimensions relate to various aspects of how the service is delivered (the functional quality to use Grönroos' terms).

Stockholm and Barcelona show different patterns, however. In Barcelona, the comfort items did not form a unique factor, but loaded fairly equally on the other three dimensions. The comfort aspects are thus not cognitively separated from the other aspects of public transport in Barcelona. Instead, comfort is integrated into the evaluation of other public transport attributes, setting this city apart from the others in our study.

In Stockholm, the staff items formed a new factor together with the comfort items. This indicates a somewhat different role regarding both comfort and staff in the public transport system of the Swedish capital, compared to the other cities. These aspects of public transport contribute toward the customer experience not as separate factors in themselves, nor as integrated parts of the service system, but as features enabling the public transport service to be delivered in a pleasant and convenient way (or perhaps the opposite). In relation to Grönroos' (2000) conceptualization, we see the formation of a unified functional quality factor that is clearer in Stockholm than in the other cities.

There are also some interesting findings as regards to how the individual items load on the factors. In comparison to models derived from other service sectors (cf. Berry, Parasuraman and Zeithaml 1985, 1988), as well as previous studies of public transport satisfaction (Bates et al. 2001, Edvardsson 1998, Friman et al. 2001, Hensher et al. 2003), the integration of supply and reliability items into a single "system" factor is the most striking difference. This indicates that the quality of the operational performance of the system and the quality of the system itself are not meaningfully separated by the customers. 
In many studies of PT satisfaction, items regarding the information given to travellers are grouped a priori as one generic dimension (BEST 2006, Edvardsson 1998, Friman \& Gärling 2001). However, in our analysis the information items did not form a unique factor, instead loading on the system and the staff factors (where available). This might be a reflection of the fact that information can be provided by both staff and (increasingly) technical solutions that are integrated into the transport system (or at least perceived in that way). The latter kind of information is increasingly replacing traditional means of mass communication with passengers, e.g. timetable booklets and bulletin boards.

\section{CONCLUSIONS}

One conclusion that can be drawn from this study is that industry characteristics should be taken into consideration when quality dimensions are discussed. Although the four general dimensions of customer-perceived quality identified in the paper resemble the findings of studies conducted in other service industries, they also express distinct circumstances relating to public transport. In particular, they reflect the heavy reliance on technology and infrastructure that is inherent in public transport operations.

A second conclusion is that there are differences within the industry, both in terms of how individual items load on dimensions, as well as in the general dimensional structure. As indicated previously, such differences might be due to variations in public transport service offerings or due to external factors such as culture and tradition. However, further studies are required in order to investigate this more thoroughly. Thus, one possible direction for future research would be to exploratively identify different patterns (as in the present study) and then investigate the statistical magnitude of the differences between them using confirmatory approaches such as structural equation modelling (Jöreskog \& Sörbom 1993).

In the meantime, the possibility of encountering such differences should be taken into account when standardized survey instruments are used in multiple public transport systems. This study shows that there are industry generic dimensions, but the exceptions also show that it is important to take local conditions into consideration. It would be very enlightening to discuss the possible reasons for the results.

One important managerial implication of this study is that practitioners need to thoroughly consider how they measure and interpret satisfaction data. Standardized instruments from the transport industry, as well as from the service sector in general could very well be used for inspiration when it comes to attributes to measure, however local conditions must be acknowledged as well. The current study highlights the important role of safety/security, system (supply and reliability), comfort, and staff behavior for traveler satisfaction, but it also shows that there are differences in how these dimensions are cognitively structured.

\section{Acknowledgements}

This research was supported by grant \#2004-02974 awarded by the Swedish Governmental Agency for Innovation Systems (VINNOVA) to the Service and Market Oriented Transport Research Group (SAMOT).

\section{References}

Beirão, Gabriela and J.A. Sarsfield Cabral. "Understanding Attitudes Towards Public Transport and Private Car: A Qualitative Study.” Transport Policy 14, (2007): 478-489.

BEST Organizing Committee. BEST Results of the 2006 Survey. Oslo, 2006. 
Buttle, F. “SERVQUAL: Review, Critique, Research Agenda.” European Journal of Marketing 30, (1996): 8-32.

Bates, John, John Polak, Peter Jones, and Andrew Cook. "The Valuation of Reliability for Personal Travel.” Transportation Research Part E 37, (2001): 191-229.

Cronin, J. Joseph and Steven A. Taylor. "Measuring Service Quality: A Reexamination and Extension.” Journal of Marketing 58, (1992): 53-66.

Edvardsson, Bo. "Causes of Customer Dissatisfaction-Studies of Public Transport by the CriticalIncident Method.” Managing Service Quality 8, (1998): 189-197.

Edvardsson, Bo. Tjänsteutveckling med inbyggd kvalitet [Service development with in-built quality]. Karlstad: Service Research Center, 1996.

European Committee for Standardization (CEN). Transportation-Logistics and Services-Public Passenger Transport-Service Quality Definition, Targeting and Measurement. Brussels, 2002.

Friman, Margareta, Bo Edvardsson and Tommy Gärling. "Perceived Service Quality Attributes in Public Transport: Inferences from Complaints and Negative Critical Incidents." Journal of Public Transport 2, (1998): 69-91.

Friman, Margareta. "Implementing Quality Improvements in Public Transport." Journal of Public Transportation 7, (2004): 49-65.

Friman, Margareta, Bo Edvardsson and Tommy Gärling. "Frequency of Negative Critical Incidents and Satisfaction with Public Transport Services. I." Journal of Retailing and Consumer Services 8, (2001): 95-104.

Friman, Margareta, and Tommy Gärling. "Frequency of Negative Critical Incidents and Satisfaction with Public Transport Services. II.” Journal of Retailing and Consumer Services 8, (2001): 105 114.

Fornell, Cleas. “A National Customer Satisfaction Barometer: The Swedish Experience.” Journal of Marketing 56, (1992): 6-21.

Fujii, Satoshi and Ryuichi Kitamura. "What Does a One-Month Free Bus Ticket do to Habitual Drivers? An Experimental Analysis of Habit and Attitude Change." Transportation 30, (2003): 8195.

Grönroos, Christian. “A Service Quality Model and Its Marketing Implications.” Journal of European Marketing 18, (1984): 36-44.

Grönroos, Christian, Grönroos, C. Service Management and Marketing: A Customer Relationship Management Approach, Chichester, Wiley, 2000.

Hair, J. F., Anderson, R. E., Tatham, R. L., Black, W. C., Multivariate Data Analyses. Macmillan, New York, 1998.

Hensher, David A., and Paola Prioni. “A Service Quality Index for Area-Wide Contract Performance Assessment.” Journal of Transport Economics and Policy 36, (2002): 93-113.

Hensher, David A., and John Stanley. "Performance-Based Quality Contracts in Bus Service Provision." Transportation Research Part A 37, (2003): 519-538. 
Perceived Satisfaction with Public Transport

Hensher, David A., Peter Stopher, and Philip Bullock. "Service Quality-Developing a Service Quality Index in the Provision of Commercial Bus Contracts." Transportation Research Part A 37, (2003): 499-517.

Hensher, David A. "Bus Transport: Economics, Policy and Planning." Research in Transportation Economics 18, (2007): 1-507.

Henson, Robin, K. and Kyle J. Roberts. "Use of exploratory factor analysis in published research. Common errors and some comments on improved practice." Educational and Psychological Measurements 66, (2006): 393-416.

Johnson, Michael, D. and Anders Gustafsson. Improving Customer Satisfaction, Loyalty and Profit: An Integrated Measurement and Management System. San Fransisco, Jossey-Bass, 2000.

Jöreskog, Karl. G., and Dag Sörbom. LISREL 8: Structural Equation Modeling with the SIMPLIS Command Language. Chicago, Scientific Software International, 1993.

Kaiser, Henry F. "The Application of Electronic Computers to Factor Analysis." Educational and Psychological Measurements 20, (1960): 141-151.

Mackett, Roger L., and Marion Edwards. "The Impact of New Public Transport Systems: Will the Expectations Be Met?” Transportation Research Part A: Policy and Practice 32, (1998): 231-245.

Morfoulaki, Maria., Yannis Tyrinopoulos, and Georgia Aifadopoulou. "Estimation of Satisfied Customers in Public Transport Systems: A New Methodological Approach." Journal of the Transportation Research Forum 46, (2007): 63-72.

Oliver, Richard L. Satisfaction. A Behavioral Perspective on the Consumer. New York, McGrawHill, 1997.

Osborne, David and Ted Gaebler. Reinventing Government: How the Entrepreneurial Spirit is Transforming the Public Sector. Reading, Addison-Wesley, 1992.

Parasuraman, A., Valarie A. Zeithaml, and Leonard L. Berry. “A Conceptual Model of Service Quality and Its Implications for Future Research.” Journal of Marketing 49, (1985): 41-50.

Parasuraman, A., Valarie A. Zeithaml, and Leonard L. Berry. "Reassessment of Expectations as a Comparison Standard in Measuring Service Quality: Implications for Future Research.” Journal of Marketing 58, (1994): 111-124.

Prioni Paola and David A. Hensher. "Measuring Service Quality in Scheduled Bus Services." Journal of Public Transportation 3, (2000): 51-74.

Teas, K.R. "Expectations, Performance Evaluation, and Consumers' Perceptions of Quality." Journal of Marketing 57, (1993): 18-24.

Wall, Graham and Mike McDonald. "Improving Bus Service Quality and Information in Winchester." Transport Policy 14, (2007): 165-179.

Zeithaml, Valarie A., Leonard L. Berry, and A. Parasuraman. "Communication and Control Processes in the Delivery of Service Quality.” Journal of Marketing 52, (1988): 35-48. 
Markus Fellesson is a researcher at the SAMOT (Service and Market Oriented Transport) research group at Karlstad University. His research focuses on various aspects of customer orientation as a managerial practice. Fellesson is co-author of Marketing Discourse - a critical perspective published by Routledge and his research has also been published in the Scandinavian Journal of Management and Revista ADM.MADE.

Associate professor Margareta Friman is a researcher and director of the SAMOT (Service and Market Oriented Transport) research group at Karlstad University. Her research focuses on perceived service quality and customer satisfaction in public transport services. Friman has been published in the Journal of Public Transportation, the Journal of Transportation Research: Part F and the Journal of Economic Psychology. 